\title{
A case of advanced lung cancer treated by surgery followed by adjuvant combination therapy of gefitinib and interleukin-2 lymphokine-activated killer cell immunotherapy
}

\author{
Takanori Ayabe $^{1)}$, Tetsuya Shimizu ${ }^{1)}$, Masaki Tomita ${ }^{1)}$, Yoshiaki Kushima ${ }^{2)}$ and Toshio Onitsuka ${ }^{1)}$ \\ ${ }^{1)}$ Department of Surgery II, Faculty of Medicine, University of Miyazaki \\ ${ }^{2)}$ Tsuruta Hospital
}

\begin{abstract}
A smoker, 55-year-old male with a small nodule in left $S^{5}$ on computed tomographic (CT) scanning of chest was diagnosed with pulmonary adenocarcinoma (cT1N0M0, c-stage IA). However, the CT scanning revealed that several small nodules on pleural surface might suspect a pleural dissemination, that is, IV-staged advanced lung cancer. The patient desired for receiving an aggressive multimodality containing of surgery, immunotherapy, and gefitinib treatment. After thoracotomy, the small pleural nodules were intraoperatively diagnosed with pleural dissemination by pathological examination. However, there was no malignant pleural effusion and intraoperative cytological examination of intrathoracic lavage resulted in a negative finding. Because of clinical N2-negative disease without malignant pleural effusion, left upper lobectomy with mediastinal lymph nodes dissection was preceded. The postoperative pathological examination disclosed pulmonary adnocarcinoma with mixed subtypes (pT1N2M1a, p-stage IV) and with micropapillary pattern. A detection test of epidermal growth factor receptor (EGFR) gene mutation revealed a positive result (L858R). As a systemic therapy, a combination chemotherapy of gemcitabine and carboplatin was performed in 2 cycles for the remained pleural dissemination. The patient received combination therapy of gefitinib and interleukin-2 lymphokine-activated killer cell immunotherapy in 6 cycles. A CT scanning of chest displayed disappearances of the remained pleural dissemination. There had been uneventful for 25 months. On the third postoperative year, a stereotactic radiotherapy surgery was performed for small three brain metastases. He had been healthy and received the gefitinib treatment for 45 months without any regrowing of the irradiated cerebral metastases and the treated pleural dissemination. The combination therapy of gefitinib and immunotherapy in the postoperative early phase would take advantage of extending the patient's progression-free survival, and also in case of the selected population of the advanced lung cancer harboring a EGFR mutation-positive.
\end{abstract}

Key Words: surgery, gefitinib, immunotherapy, micropapillary, advanced lung cancer

(Received January 16, 2012; Accepted March 19, 2012)

\section{Introduction}

Adjuvant therapy with anticancer drugs or radiation may inhibit tumor cell growth but simultaneously suppress host immune mechanisms ${ }^{1,2)}$ and indirectly induce cancer cells to recur or metastasize to distant organs. Considering the possible dual effects of adjuvant chemotherapy or radiotherapy, Kimura $\mathrm{H}$ et al. ${ }^{3)}$ tried to restore host immunity by adoptively transferring immune lymphocytes and interleukin (IL)-2 after adjuvant therapy. Adoptive immunotherapy with IL-2 and lymphokineactivated killer (LAK) cells combined with chemotherapy or radiotherapy improved the survival of patients after surgical resection of primary lung carcinoma ${ }^{3)}$. We

Address correspondence to: Takanori Ayabe. Department of Surgery II, Faculty of Medicine, University of Miyazaki, Kiyotake, Miyazaki, Miyazaki, 889-1692, Japan. TEL: +81-985-85-2291, FAX: +81-985-85-5563, E-mail: tayabe@med.miyazaki-u. ac.jp report a case of surgery followed by combination therapy of gefitinib (IRESSA ${ }^{\mathrm{TM}}$, AstraZeneka, Osaka, Japan) and immunotherapy for the advanced lung cancer (pT1N2M1a, p-stage IV, EGFR mutation-positive, adenocarcinoma with micropapillary pattern).

\section{Case report}

A smoker, 55-year-old male was pointed out of an abnormal shadow on X-ray film and of a small nodule in left $\mathrm{S}^{5}$ on computed tomographic (CT) scanning of chest by medical examination, however, which nodule had been tightly followed up as an old inflammatory scar. The twenty months later, the pulmonary nodule had increased in size, fluorodeoxyglucose positron emission tomography showed an abnormal accumulation. In December, 2007, he was admitted to our hospital and diagnosed with pulmonary adenocarcinoma by transbronchial lung biopsy from left $\mathrm{B}^{5}$ bronchus (cT1N0M0, 
c-stage IA). The level of carcinoembryonal antigen (CEA) was within normal limits $(4.7 \mathrm{ng} / \mathrm{ml})$. A CT scanning of chest displayed $22 \mathrm{~mm}$ of nodule in left $\mathrm{S}^{5}$ and no mediastinal lymphadenopathy (Fig. 1a). However, several small nodules (Fig. 1a) were revealed on pleural surface without pleural effusion, which findings might suspect a pleural dissemination, that is, IV-staged advanced lung cancer. The patient desired for receiving an aggressive multimodality therapy containing of standard surgical treatment and immunotherapy combined with gefitinib for the advanced primary cancer.

After thoracotomy, the small pleural nodules were intraopearively diagnosed with pleural dissemination (M1a) by a pathological examination (Fig. 1b), however, malignant pleural effusion had not been recognized. An intraoperative cytology of intrathoracic lavage showed a negative result of malignancy. Because of the clinical N2-negative disease without malignant pleural effusion, left upper lobectomy with mediastinal lymph nodes dissection was preceded. As a result, the postoperative pathological examination disclosed adnocarcinoma with mixed subtypes of the lung (p3, D2, E0, PM0, pT1N2M1a, p-stage IV), which showed micropapillary pattern (Fig. 2a, 2b). The dissected lymph nodes were confirmed as metastasis in station 4, 5, 6, 7, 10, and 11. A detection test ${ }^{4}$ of EGFR gene mutation showed a positive result (L858R).

As a systemic treatment for the remained pleural dissemination, adjuvant chemotherapy of gemcitabine and carboplatin was performed in 2 cycles. As secondline adjuvant therapy, an oral administration of gefitinib (IRESSA $^{\mathrm{TM}}$, Astrazeneka, Osaka, Japan) was started in April, 2008. Afer the admintstration of gefitinib, facial dermatitis was recognized but the patient did not need its rash management. In May, 2009, the patient received a lymphokine-activated killer (LAK) cell immunotherapy, which modality was performed in 6 cycles in another hospital (Fig. 3). LAK cells were produced from peripheral blood lymphocytes and consist mainly of activated NK cells. This immunotherapy has been described in detail elsewhere ${ }^{5,6)}$. There were no serious side effects such as fever on the day after administration of LAK cells. During the combination therapy of gefitinib and immunotherapy, there were no side effects suggestive of viral or bacterial infection caused by LAK cells and were no worsening of skin rash caused bv gefitinib treatment. There had been uneventful during the combination therapy of immunotherapy and gefitinib. A CT followup scanning of chest displayed shrinkages or disappearances of the pleural disseminated lesions (Fig. 4a, 4b). On the 25th postoperative month, local recurrence and distant metastasis had not been detected, the disseminated lesions had obtained a long stable disease. On the third postoperative year, three small cerebral metastases had been found in caudate nucleus (Fig. 5a), thalamus, and frontal lobe. Because the patient rejected to receive whole brain radiotherapy, a sterotactic radiological surgery had been performed for three metastatic lesions, respectively. He had been healthy with a good quality of life and could maintain the treatment of gefitinib for 45 months without regrowing of the irradiated brain metastases (Fig. 5b) and the treated pleural disseminated lesions.

\section{Discussion}

Overall outcome from standard tri-modality therapy of surgery, chemotherapy, and radiotherapy for lung cancer remains poor. As the fourth modality, immunotherapy could have an important role to play in the treatment of lung cancer. Initially, IL-2 LAK adoptive immunotherapy was regarded as a powerful and ideal therapy effective for patients in any condition with any kind of malignant diseases ${ }^{7,8)}$. Kimura et al. ${ }^{6}$ used adoptive immunotherapy in 82 patients following curative resection. The patients were randomized to receive IL-2 and LAKs following two course of combination chemotherapy (cisplatin, vindesine, and mitomycin) or chemotherapy alone. The 5- and 7-year survival rates of the chemo-immunotherapy group and chemotherapy group were $58.2 \%$ and $31.5 \%$, respectively in stage II and IIIA patients. This difference was statistically significant $(\mathrm{P}=0.0038)$. In patients undergoing non-curative resection, Kimura et al. ${ }^{5)}$ reported a survival benefit for the immunotherapy arm (IL-2 and LAK) following randomization of 105 patients to chemotherapy, radiotherapy or immunotherapy. The 7-year survival rate was greater in the immunotherapy group compared with the chemotherapy and chemo-radiotherapy groups $(39.1 \%, 12.7 \%, \mathrm{P}<0.01)$. In a phase III randomized study ${ }^{3)}$, adoptive immunotherapy with IL-2 and LAK cells combined with chemotherapy or radiotherapy improved the survival of patients after surgical resection of primary lung carcinoma, which was compared with control standard therapy. In this case, the reason for the selection of immunotherapy was depended on the patient's desire as the forth modality.

On the other hand, on the treatment of gefitinib, EGFR mutation examination is widespread at academic medical centers and in some local clinics in community practice. The American Society of Clinical Oncology (ASCO) 2009 Guideline Update on stage IV NSCLC addresses the use of EGFR-TKIs in the second- and thirdline settings ${ }^{9}$. One large phase III trial (the Iressa PanAsia Study [IPASS] trial) ${ }^{10-12)}$, three smaller phase III randomized controlled trials using progression-free survival as the primary end point ${ }^{13-15)}$, and one small phase III trial with overall survival as the primary endpoint ${ }^{16)}$, all involving first-line EGFR-TKIs and chemotherapy doublets, form the basis of the provisional clinical opinion. That is, on the basis of the results of five phase III 

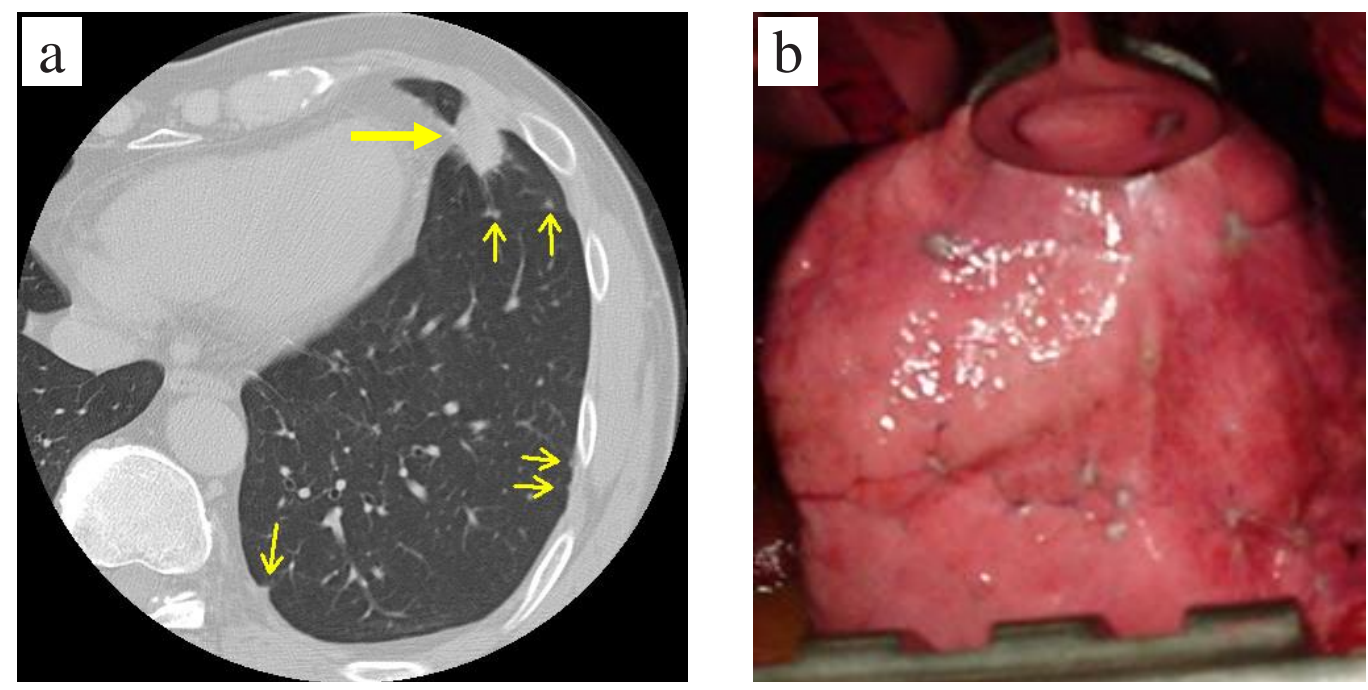

Fig. 1 a. Computed tomographic (CT) scanning of chest showing a lung cancer (left $\mathrm{S}^{5}, 22 \mathrm{~mm}$ ) (bold arrow) and suspected intrathoracic dissemination (M1a) (thin arrows).

b. Intraoperative photo. The pleural surface of left lower lobe showing a dissemination, which was diagnosed with adenocarcinoma (M1a, IV-stage). An intraoperative cytology of intrathoracic lavage revealed a negative finding.
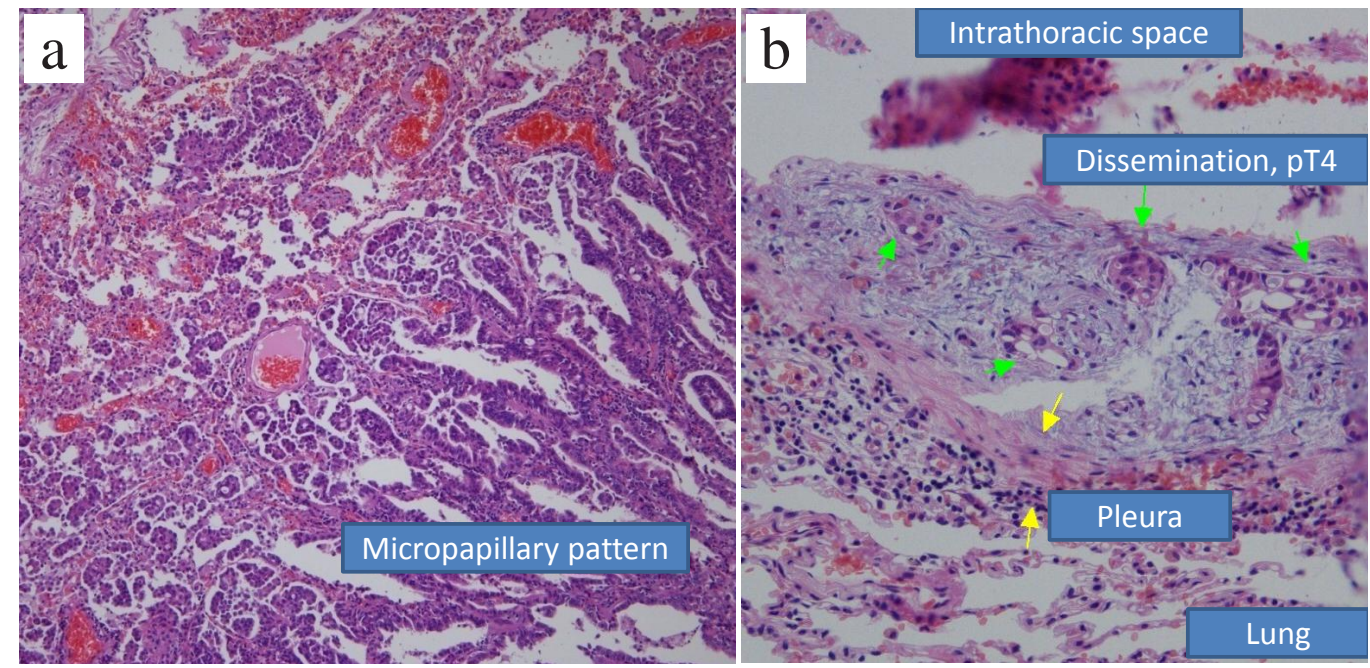

Fig. 2. Postoperative pathology.

a. In the tumor tissue in left $S^{5}$, cancer cells proliferated in papillary, acinar and bronchioalveolar pattern with desmoplastic stroma. Micropapillary pattern was associated in part. Lymphatic and vascular permeation was also seen. Adenocarcinoma of the mixed subtypes (papillary, acinar, bronchioalveolar type) was considered.

b. Apart from the tumor, a cancer nodule was found, probably showing dissemination (green arrows).
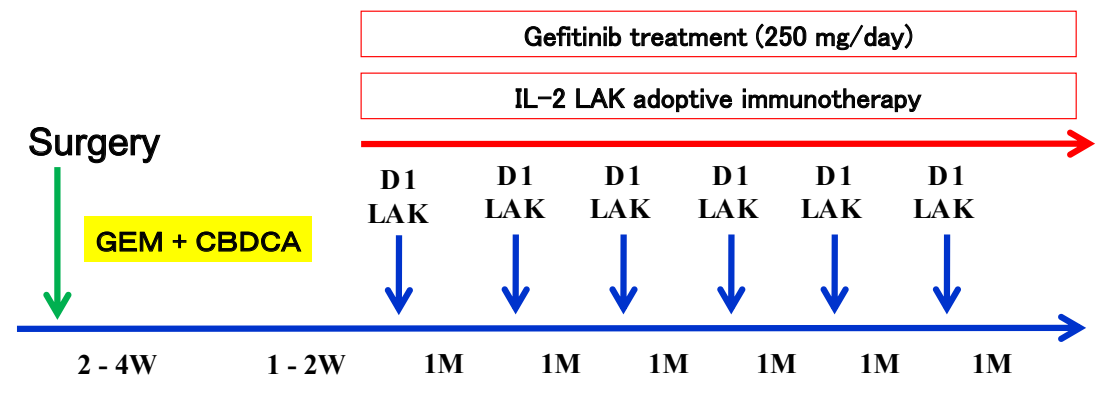

Fig. 3. The time course of treatment schedule.

Adjuvant chemotherapy of gemcitabine and carboplatin was performed in 2 cycles after surgery. Adjuvant interleukin-2 lymphokine-activated killer cell immunotherapy (IL-2 LAK) had been performed in 6 cycles for 6 months. Simultaneously, adjuvant administration of gefitinib treatment has been performed for more than 3 years. 

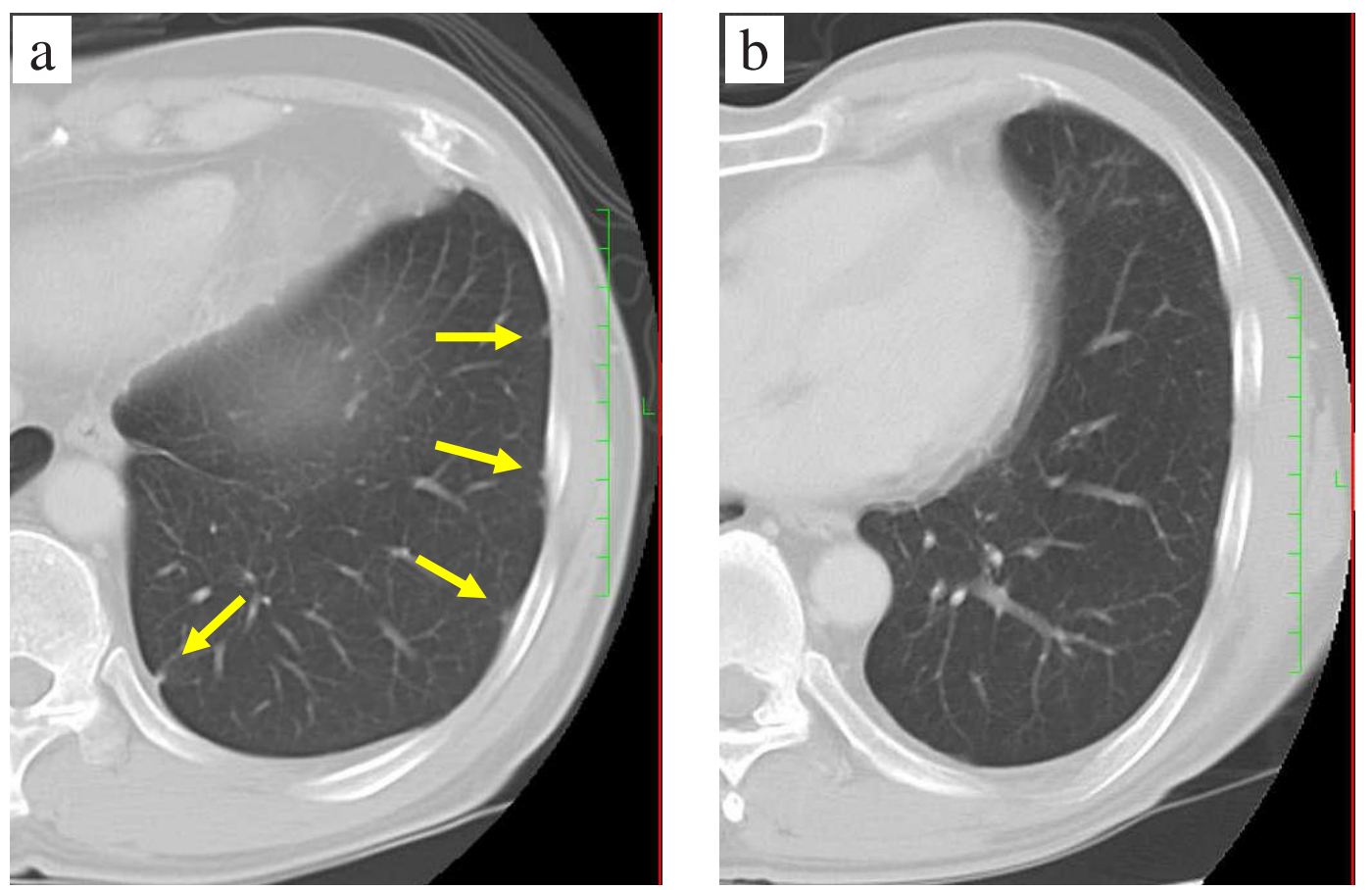

Fig. 4. A CT scanning of chest.

a: Preoperative lower lobe before adjuvant therapy of gefitinib and immunotherapy. Pleural dissemination was displayed (arrows).

b: Postoperative lower lobe after adjuvant therapy of gefitinib and immunotherapy. The remained pleural dissemination had been partly unclear or disappeared.
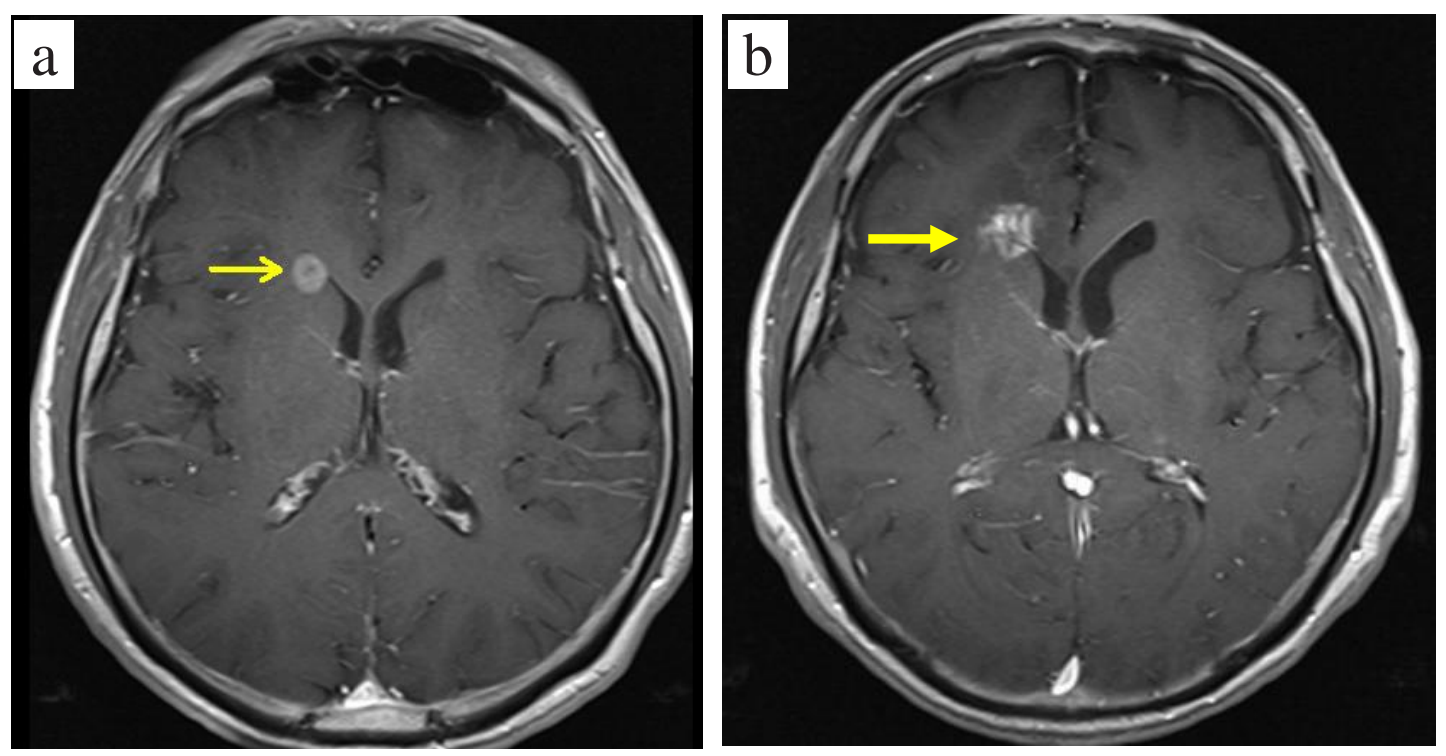

Fig. 5. The most largest cerebral metastasis detected by postoperative magnetic resonance imaging of brain.

a: Pre-stereotactic radiological surgery (in Feb., 2010). The small cerebral metastasis was found in caudate nucleus (arrow).

b: Post-stereotactic radiological surgery (in Nov., 2011). The irradiated small metastatic lesion has not been regrowing and showed radiologic necrosis with edema (arrow). 
randomized controlled trials, patients with NSCLC who are being considered for the first-line therapy with an EGFR-TKI (patient who have not previously received chemotherapy or an EGFR-TKI) should have their tumor tested for EGFR mutations to determine whether an EGFR-TKI or chemotherapy is the appropriate first-line therapy $^{17)}$.

The role of gefitinib in first-line therapy for patients with known EGFR mutations was confirmed in the randomized Phase III Iressa Pan-Asia Study (IPASS) ${ }^{10)}$. Gefitinib group demonstrated superior progression-free survival than carboplatin-paclitaxel group (HR: 0.74; 95\% CI: $0.65-0.85 ; \mathrm{P}<0.0001)$ in the overall population. Most importantly, the PFS of the subgroup of patients with EGFR mutations was significantly better than that of the overall population who received gefitinib alone (HR: 0.48 ; 95\% CI: $0.36-0.64 ; \mathrm{p}<0.0001$ ). Patients without EGFR mutations had detrimental effects from treatment with first-line gefitinib (HR: 2.86; 95\% CI: 2.05 - 3.86; $\mathrm{p}<0.0001$ ). Our case harbored a EGFR-mutation and could continue more than 3 years without any adverse events.

A micropapillary pattern is defined as a pattern showing micropapillary structures without a fibrovascular core. It is well known that the presence of a micropapillary pattern leads to a poorer prognosis in lung adenocarcinoma $^{18-23)}$. This adenocaricnoma frequently metastasizes to lymph nodes, shows pleural invasion and follows an aggressive clinical course ${ }^{18,21,23)}$. However, little is known about the mechanisms involved in micropapillary-pattern-associated lymph node metastasis. It is still unclear how small micropapillary clusters of carcinoma cells present in tumoral alveolar spaces invade lymphatics and lead to increased lymph node metastasis. Our case showed the micropapillary pattern and resulted in advanced cancer such as multiple dissemination and lymph nodal metastasis in multistation. Generally, the prognosis of the cancers with micropapillary pattern had been known to be poor, however, in this case of advanced lung cancer, combination therapy of gefitinib and immunotherapy might enable the patient to have more than 3 years of PFS.

In our case, preoperatively, the lung cancer was suspected with stage IV disease with pleural dissemination by chest CT scanning. However, the patient desired for receiving an aggressive multimodality therapy containing of standard surgical treatment, chemotherapy, molecular-targeted therapy, and immunotherapy for the advanced primary cancer. The reason why we performed standard lobectomy was caused by clinical N2-negative disease without malignant pleural effusion and also by the discrepancy of intraoperative cytological negative result of intrathoracic lavage and the pathological positive result of dissemination. In this case, as an operative procedure, generally, a partial resection or a simple lobectomy should be selected in considering of the curability of the advanced cancer and of the postoperative pulmonary function. However, the patient was young age and a degree of the decreased quality of life could be permitted and he expected to the possibility of the benefit from the adjuvant combination therapy, that is, adjuvant immunotherapy and molecular-targeted therapy, for the disseminated disease. Lobectomy with lymph nodal dissection was the first step to reduce the volume of cancer cells of primary tumor and the mediastinal lymph nodal metastasis as possible. The intrathoracic residual disseminated lesions and the suspected lymphatic and/or distant micrometastases were the next targets of this adjuvant chemotherapy, gefitinib, and LAK therapy. There are some merits derived from administering chemotherapy before immunotherapy, which might also contribute to reducing tumor volume of dissemination or to damaging the residual tumor cells. As a multimodality therapy, immunotherapy in conjunction with adjuvant molecular-targeted therapy of gefitinib was added to improve the patient's postsurgical survival. After cytotoxic chemotherapy, immunosuppressive agents or procedures, such as anticancer drugs, are also toxic to host immune cells and may well be effective in eliminating or inhibiting suppressor cells or suppressive factors that inhibit the function of killer cells ${ }^{3)}$. It is also conceivable that the Fas antigen induced by chemotherapy may be recognized by LAK cells and induce apoptosis of tumor cells ${ }^{24,25)}$. To prevent a recurrence, LAK immunotherapy would play a role of recovering and enhancement of the suppressive host-immune system in the post-chemotherapy period.

This patient is alive 45 months after surgery and immunochemotherapy. It can be considered as long surivivor in advanced non-small cell lung cancer. The 5-year overall survival of pathological stage IV for the proposed International Association for the Study of Lung Cancer (IASLC) stage grouping was reported to be $13 \%$ and median survival time (MST) was 17 months ${ }^{26)}$. On descriptors of distant metastasis (M descriptors), M1a subgroup includes patients with either pleural dissemination or contralateral pulmonary nodules and an M1b subgroup with distant metastases, the 5-year survival of M1a (pleural effusion) was $6 \%$ and MST was 10 months ${ }^{26)}$. This patient is uncommon long survivor by comparison with previous survival data of advanced or non-small lung cancer based on clinical trial with dissemination and distant metastasis.

Lastly, extraordinarily, this patient was an advanced case with staged IV, dissemination, lymph nodal metastases in multistation, and micropapillary pattern. However, an aggressive multimodality therapy of surgery, immunotherapy, gefitinib enabled the patient to maintain a more than 3 years of good quality of life, in spite of carrying with brain metastasis. 


\section{References}

1) Campbell AC, Hersey P, Harding B, Hollingsworth PM, Skinner J, MacLennan IC. (1973) Effects of anti-cancer agents on immunological status. Br J Cancer 28 (Suppl): 254-261.

2) Roth JA, Eilber FR, Morton DL. (1978) Effect of Adriamycin and high-dose methotrexate chemotherapy on in vivo and in vitro cellmediated immunity in cancer patients. Cancer 41: 814-819.

3) Kimura H, Yamaguchi Y. (1997) A phase III randomized study of Interleukin-2 Lymphokine-Activated Killer Cell Immunotherapy Combined with chemotherapy or radiotherapy after curative or noncurative resection of primary lung carcinoma. Cancer 80: 42 49.

4) Naoki K, Soejima K, Okamoto H, Hamamoto J, Hida N, Nakach I, Yasuda H, Nakayama S, Yoda S, Satomi R, Ikemura S, Terai H, Sato T, Watanabe K. (2011) The PCR-invader method (structurespecific 5' nuclease-based method), a sensitive method for detecting EGFR gene mutations in lung cancer specimens; comparison with direct sequencing. Int J Clin Oncol 16: 335-344.

5) Kimura H and Yamaguchi Y. (1995) Adjuvant immunotherapy with interleukin-2 and lymphokine-activated killer cells after noncurative resection of primary lung cancer. Lung Cancer 13: 31-44.

6) Kimura H and Yamaguchi Y. (1996) Adjuvant chemo-immunotherapy after curative resection of Stage II and IIIA primary lung cancer. Cancer 14: 301-314.

7) Rosenberg SA, Lotze MT, Muul LM, Leitman S, Chang AE, Ettinghausen SE, Matory YL, Skibber JM, Shiloni E, Vetto JT, et al. (1985) Observations on the systemic administration of autologous lymphokine-activated killer cells and recombinant interleukine-2 in patients with metastatic cancer. N Eng J Med 313: 1485 1492

8) Rosenberg SA, Lotze MT, Muul LM, Chang AE, Avis FP, Leitman S, Linehan WM, Robertson CN, Lee RE, Rubin JT, et al. (1987) A progress report on the treatment of 157 patients with advanced cancer using lymphokine-activated killer cells and interleukin-2 or high dose interleukin-2 alone. N Eng J Med 316: 889-897.

9) Azzoli CG, Baker S Jr, Temin S, Pao W, Aliff T, Brahmer J, Johnson DH, Laskin JL, Masters G, Milton D, Nordquist L, Pfister DG, Piantadosi S, Schiller JH, Smith R, Smith TJ, Strawn JR, Trent D, Giaccone G; American Society of Clinical Oncology. (2009) American Society of Clinical Oncology. American Society of Clinical Oncology Clinical Practice Guideline update on chemotherapy for stage IV non-small-cell lung cancer. J Clin Oncol 27: 6251-6266.

10) Mok TS, Wu YL, Thongprasert S, Yang CH, Chu DT, Saijo N, Sunpaweravong P, Han B, Margono B, Ichinose Y, Nishiwaki Y, Ohe Y, Yang JJ, Chewaskulyong B, Jiang H, Duffield EL, Watkins CL, Armour AA, Fukuoka M. (2009) Gefitinib or carboplatinpaclitaxel in pulmonary adenocarcinoma. N Engl J Med 361: $947-$ 957.

11) Yang CH, Fukuoka M, Mok TS, et al. (2010) Final overall survival (OS) results from a phase III, randomised, openlabel, first-line study of gefitinib $(\mathrm{G}) \mathrm{v}$ carboplatin/paclitaxel $(\mathrm{C} / \mathrm{P})$ in clinically selected patients with advanced nonsmall cell lung cancer (NSCLC) in Asia (IPASS). Ann Oncol 21: viii1-viii2, (suppl 8).

12) Fukuoka M, Wu Y, Thongprasert S, et al. (2009) Biomarker analyses from a phase III, randomized, openlabel, first-line study of gefitinib $(\mathrm{G})$ versus carboplatin/ paclitaxel $(\mathrm{C} / \mathrm{P})$ in clinically selected patients (pts) with advanced non-small cell lung cancer (NSCLC) in Asia (IPASS). J Clin Oncol 27: 408s, (suppl; abstr 8006).

13) Lee JS, Park K, Kim SW. (2009) A randomized phase III study of gefitinib versus standard chemotherapy (gemcitabine plus cisplatin) as a first-line treatment for neversmokers with advanced or metastatic adenocarcinoma of the lung. 13th World Conference on Lung Cancer, San Francisco, July 31-August 4, (abstr PRS.4).
14) Maemondo M, Inoue A, Kobayashi K, Sugawara S, Oizumi S, Isobe H, Gemma A, Harada M, Yoshizawa H, Kinoshita I, Fujita Y, Okinaga S, Hirano H, Yoshimori K, Harada T, Ogura T, Ando M, Miyazawa H, Tanaka T, Saijo Y, Hagiwara K, Morita S, Nukiwa T; North-East Japan Study Group. (2010) North-East Japan Study Group. Gefitinib or chemotherapy for non-small-cell lung cancer with mutated EGFR. N Engl J Med 362: 2380-2388.

15) Mitsudomi T, Morita S, Yatabe Y, Negoro S, Okamoto I, Tsurutani J, Seto T, Satouchi M, Tada H, Hirashima T, Asami K, Katakami N, Takada M, Yoshioka H, Shibata K, Kudoh S, Shimizu E, Saito H, Toyooka S, Nakagawa K, Fukuoka M; West Japan Oncology Group. (2010) Gefitinib versus cisplatin plus docetaxel in patients with non-small-cell lung cancer harbouring mutations of the epidermal growth factor receptor (WJTOG3405): an open label, randomised phase 3 trial. Lancet Oncol 11: 121-8.

16) Zhou C, Wu YL, Chen G. (2010) Efficacy results from the randomised phase III OPTIMAL (CTONG 0802) study comparing first-line erlotinib versus carboplatin (CBDCA) plus gemcitabine (GEM), in Chinese advanced non-small-cell lung cancer (NSCLC) patients (PTS) with EGFR activating mutations. Ann Oncol (suppl 8): 21:6.

17) Keedy VL, Temin S, Somerfield MR, Beasley MB, Johnson DH, McShane LM, Milton DT, Strawn JR, Wakelee HA, Giaccone G. (2011) American Society of Clinical Oncology provisional clinical opinion: epidermal growth factor receptor (EGFR) Mutation testing for patients with advanced non-small-cell lung cancer considering first-line EGFR tyrosine kinase inhibitor therapy. J Clin Oncol. 29: 2121-2127.

18) Amin MB, Tamboli P, Merchant SH, Ordóñez NG, Ro J, Ayala AG, Ro JY. (2002) Micropapillary component in lung adenocarcinoma: a distinctive histologic feature with possible prognostic significance. Am J Surg Pathol 26: 358-364.

19) Chantranuwat C. (2004) Metastatic potentiality of micropapillary and conventional histological pattern: a comparative study of 82 pulmonary adenocarcinomas. J Med Assoc Thai 87 (Suppl 2): S255-S260.

20) Hoshi R, Tsuzuku M, Horai T, Ishikawa Y, Satoh Y. (2004) Micropapillary clusters in early-stage lung adenocarcinoma: a distinct cytologic sign of significantly poor prognosis. Caner 102:8186.

21) Makimoto Y, Nabeshima K, Iwasaki H, Miyoshi T, Enatsu S, Shiraishi T, Iwasaki A, Shirakusa T, Kikuchi M. (2005) Micropapillary pattern: a distinct pathological marker to subclassify tumours with a significantly poor prognosis within small peripheral lung adenocarcinoma $(</=20 \mathrm{~mm})$ with mixed bronchioloalveolar and invasive subtype (Noguchi's type C tumours). Histopathology 46: 677-684.

22) Miyoshi T, Satoh Y, Okumura S, Nakagawa K, Shirakusa T, Tsuchiya E, Ishikawa Y. (2003) Early-stage lung adenocarcinomas with a micropapillary pattern, a distinct pathologic marker for a significantly poor prognosis. Am J Surg Pathol 27:101-109.

23) Roh MS, Lee JI, Choi PJ, Hong YS. (2004) Relationship between micropapillary component and micrometstasis in the regional lymph nodes of patients with stage I lung adenocarcinoma. Histopathology 45: 580-586.

24) Hanabuchi S, Koyanagi M, Kawasaki A, Shinohara N, Matsuzawa A, Nishimura Y, Kobayashi Y, Yonehara S, Yagita H, Okumura K. (1994) Fas and its ligand in a general mechanism of T-cellmediated cytotoxicity. Proc Natl Acad Sci USA 91: 4930-4.

25) Montel AH, Bochan MR, Hobbs JA, Lynch DH, Brahmi Z. (1995) Fas involvement in cytotoxicity mediated by human NK cells. Cell Immunol 166: 236-46.

26) Detterbeck FC, Boffa DJ, Tanoue LT. (2009) The new lung cancer staging system. Chest 136: 260-71. 